\title{
Serra da Estrela cheese's free amino acids profiles by UPLC-DAD-MS/MS and their application for cheese origin assessment
}

\author{
M.J. Reis Lima ${ }^{\mathrm{a}, \mathrm{b}}$, Andréia O. Santos ${ }^{\mathrm{c}, \mathrm{d}}$, Soraia Falcão ${ }^{\mathrm{e}}$, Luísa Fontes ${ }^{\mathrm{b}}$, Edite Teixeira-Lemos ${ }^{\mathrm{a}, \mathrm{b}}$, \\ Miguel Vilas-Boas ${ }^{\mathrm{e}}$, Ana C.A. Veloso ${ }^{\mathrm{d}, \mathrm{f}}$, António M. Peres ${ }^{\mathrm{c}, \mathrm{e}, *}$ \\ ${ }^{\text {a }}$ Center for Studies in Education, Technology and Health (CI\&DETS) and Research Centre for Natural Resources, Environment and Society (CERNAS), Polytechnic Institute \\ of Viseu, Quinta da Alagoa - Estrada de Nelas, Ranhados, 3500 - 606 Viseu, Portugal \\ ${ }^{\mathrm{b}}$ Department of Food Science, Agrarian School of Viseu, Polytechnic Institute of Viseu, Quinta da Alagoa - Estrada de Nelas, Ranhados, 3500 - 606 Viseu, Portugal \\ ${ }^{\mathrm{c}}$ Laboratory of Separation and Reaction Engineering - Laboratory of Catalysis and Materials (LSRE-LCM), ESA, Instituto Politécnico de Bragança, Campus Santa \\ Apolónia, 5300-253 Bragança, Portugal \\ ${ }^{\mathrm{d}}$ CEB - Centre of Biological Engineering, University of Minho, Campus de Gualtar, 4710-057 Braga, Portugal \\ e Centro de Investigação de Montanha (CIMO), Instituto Politécnico de Bragança, Campus de Santa Apolónia, 5300-253 Bragança, Portugal \\ ${ }^{\mathrm{f}}$ Instituto Politécnico de Coimbra, ISEC, DEQB, Rua Pedro Nunes, Quinta da Nora, 3030-199 Coimbra, Portugal
}

\section{A R T I C L E I N F O}

\section{Keywords:}

Serra da Estrela cheese

Amino acids profiles

UPLC-DAD-MS/MS

Origin assessment

Chemometrics

\begin{abstract}
A B S T R A C T
Serra da Estrela cheese is a high-value Portuguese Protected Designation of Origin cheese, produced with raw ewe milk. Thus, information regarding its composition is of utmost relevance for both consumers and certified producers. In this work, the chromatographic profiles of free amino acids in cheeses (45 days of maturation, 6 producers located in 5 municipalities and produced from November 2017 to March 2018) were established by UPLC-DAD-MS/MS. The proposed method allowed detecting 19 free amino acids and cystine with overall limits of detection and quantification lower than $44 \mu \mathrm{mol} / \mathrm{L}(1.4 \mathrm{mg} / 100 \mathrm{~g}$ cheese, wet matter) and than $134 \mu \mathrm{mol} / \mathrm{L}$ ( $4.2 \mathrm{mg} / 100 \mathrm{~g}$ cheese, wet matter), respectively. In all cheeses, 17 free amino acids were quantified including 8 essential amino acids (histidine, leucine-isoleucine, lysine, methionine, phenylalanine, threonine, tryptophan and valine) and 9 non-essential amino acids (arginine, asparagine, aspartic acid, cysteine, glutamic acid, glutamine, proline, serine and tyrosine). The amounts of the free amino acids, essential free amino acids, branched chain free amino acids (leucine, isoleucine and valine) plus the free amino acids ratios (mg/g protein) were further used to identify the producer of Serra da Estrela cheeses. Linear discriminant analysis coupled with the simulated annealing variable selection algorithm was used allowing the correct classification of $96 \%$ and $90 \pm 8 \%$ of the samples, for leave-one-out and repeated K-fold cross-validation procedures, respectively. The satisfactory predictive performance pointed out the possibility of using cheeses' amino acids profiles as origin biomarkers for authenticity control, warranting the correctness identification of the cheese producer/brand, which is quite relevant for ensuring the consumer confidence and satisfaction when purchasing this high-value dairy food.
\end{abstract}

\section{Introduction}

Traditional cheeses bearing the Protected Designation of Origin (PDO) label are very appreciated worldwide and, besides the local economic impact, they have a huge social importance, allowing to preserve a know-how centenarian heritage. Cheese is a food product rich in nutritionally controversial saturated fatty acids. On the other hand, the proteolysis along the cheese ripening, leads to the formation of substances like amino acids (e.g., arginine, proline, serine, asparagine, etc.), which play a key role on cheese flavor (Tavaria, Franco,
Carballo, \& Malcata, 2003). Furthermore, amino acids, namely essential amino acids are highly important from a nutritional point of view and on food quality evaluation (Tessari, Lante, \& Mosca, 2016), being their relative contents in the food protein of utmost relevance considering the recommended daily intake of amino acids in adults (Brestenský, Nitrayová, Patráš, \& Nitray, 2018). Moreover, the intake of some essential amino acids, namely the branched chain amino acids (e.g., leucine, isoleucine and valine) may lead to beneficial health effects (Almeida et al., 2016). Thus, within the context of the potential benefits related with protein intakes, the knowledge of the amino acids levels in

\footnotetext{
* Corresponding author at: Centro de Investigação de Montanha (CIMO), Instituto Politécnico de Bragança, Campus Santa Apolónia, 5300-253 Bragança, Portugal.

E-mail address: peres@ipb.pt (A.M. Peres).
} 
foods assumes a key importance as well as the evaluation of the free amino acids contents. In which concerns Serra da Estela cheese production, it is limited to a well-defined Portuguese territorial region and time-period (from December to May) and must fulfill several requirements such as the use of raw ewe milk obtained from "Churra Mondegueira" and "Bordaleira" autochthonous breeds, which must be coagulated using the wild thistle flower (Cynara cardunculus L.) (Guiné, Tenreiro, Correia, Correia, \& Barracosa, 2016). In this study it was intended to establish the profiles of the free amino acids in Serra da Estrela cheeses, using an ultra-performance liquid chromatography coupled to a diode-array detector and electrospray ionization mass spectrometer (UPLC-DAD-MS/MS). It was also aimed to explore the possibility of using the sum of the free amino acids levels ( $\Sigma F A A)$, the sum of the essential free amino acids ( $E$ EFAA), the sum of the branched chain free amino acids ( $\Sigma \mathrm{BCFAA}$ ) as well as the free amino acids ratios (FAAratio) as putative preliminary discriminative variables for assessing cheese origin. The latter ratios (FAAratio) are determined by dividing the amount of each amino acid by the total protein content, which can be viewed as a normalization technique that minimizes the fact that cheeses usually present different moisture contents. For that, a chemometric approach based on linear discriminant analysis (LDA) coupled with the simulated annealing (SA) meta-heuristic variable selection algorithm was implemented to identify the most powerful discriminating free amino acids-based parameters. Recently, it was shown that fatty acids could be used to discriminate Serra da Estrela cheeses according to the producer, the geographical origin or the cheese production date (Reis Lima, Bahri, et al., 2019). On the other hand, amino acids profiles together with other physicochemical data were successfully applied, for example, to distinguish between PDO and non-PDO Grana Padano cheeses, (Rocchetti et al., 2018), PDO and non-PDO longripened Caciocavallo cheeses (Succi et al., 2016) or to classify Cheddar cheese based on flavor quality (Subramanian, Harper, \& RodriguezSaona, 2009). Also, it has been reported that amino acids could be used as cheese ripening process markers, based on studies carried out in Cheddar cheese (Ochi et al., 2013). Thus, finding possible geographical origin biomarkers is of paramount significance for ensuring the consumers' confidence when purchasing this high-value PDO cheeses as well as for promoting a transparent commercial competition between cheese producers.

\section{Materials and methods}

\subsection{Serra da Estrela cheese samples}

Twenty-four Serra da Estrela cheeses $(\sim 1 \mathrm{~kg})$, produced between November 2017 and March 2018, were acquired after 45 days of maturation (i.e., from January to May 2018), from 6 selected certified producers (coded as Producer 1-6), and immediately transported, in refrigerated boxes, to the laboratory, being then split in different portions, which were frozen $\left(-40^{\circ} \mathrm{C}\right)$ until analysis. As previously described (Reis Lima, Bahri, et al., 2019), the cheeses were produced with raw ewe milk ("Churra Mondegueira" and "Bordaleira" autochthonous breeds), being the dairy industries located in 5 Portuguese municipalities within the delimited PDO region (Celorico da Beira - CB, Gouveia - G, Nelas - N, Oliveira do Hospital - OH, and Penalva do Castelo - PC). In total, 48 independent samples were studied (two samples per cheese), according to: Producer $1-5$ cheeses $\times 2$ collected in November 2017, December 2017, January 2018, February 2018 and March 2018; Producer $2-3$ cheeses $\times 2$ collected in November 2017, February 2018 and March 2018; Producer $3-3$ cheeses $\times 2$ collected in December 2017 and March 2018; Producer $4-4$ cheeses $\times 2$ collected in December2017, February 2018 and March 2018; Producer 5 - 5 cheeses $\times 2$ collected in November 2017, January 2018, February 2018 and March 2018; Producer $6-4$ cheeses $\times 2$ collected in November 2017, December 2017, February 2018 and March 2018. It should be stated that (data not shown), the studied cheeses had moisture contents varying from 44 to $52 \%$, total fat levels ranging from 20 to $30 \%$, total protein contents of 19 to $25 \%$ and salt contents between 1 and $2 \%$, which were obtained using a NIRMaster ${ }^{\mathrm{TM}}$ spectrophotometer (Buchi NIRSolutions $^{\mathrm{TM}}$, Flawil, Switzerland) as previously reported (Reis Lima, Fontes, et al., 2019).

\subsection{UPLC-DAD-MS/MS analysis: amino acids detection and quantification}

\subsubsection{Reagents}

A LAA21-L-amino acids kit was purchased from Sigma-Aldrich Chemie (Steinhein, Germany) which included the following amino acids (AA) standards: L-Alanine, L-Arginine monohydrochloride, LAsparagine, L-Aspartic acid, L-Cystine, L-Cysteine hydrochloride, Glycine, L-Glutamic acid, L-Glutamine, L-Histidine monohydrochloride monohydrate, L-Isoleucine, L-Leucine, L-Lysine monohydrochloride, LMethionine, L-Phenylalanine, trans-4-Hydroxy-L-proline, L-Serine, LTyrosine, L-Threonine, L-Tryptophan, L-Valine, and N-Acetyl-LTyrosine. All other reagents/solvents were of analytical grade purity, and purchased from Fischer Chemical Scientific (Loughborough, United Kingdom). Water was obtained from a Milipore Milli-Q system, with a reverse osmosis and ion exchange filtration steps.

\subsubsection{Chromatography instrumentation and analysis conditions}

The chromatographic analysis was carried out in an UPLCDAD-MS/MS chromatographic system (Dionex Ultimate 3000 UPLC instrument from Thermo Scientific, USA) equipped with a diode-array detector (DAD) and coupled to Linear Ion Trap LTQ XL mass spectrometer (ThermoFinnigan, San Jose, CA, USA) with an ESI source. The chromatographic separation was performed using a U-VDSpher PUR C18-E $(100 \mathrm{~mm} \times 2.0 \mathrm{~mm}$ id, $1.8 \mu \mathrm{m})$ column (VDS optilab, Germany), at $40{ }^{\circ} \mathrm{C}$. The mobile phase comprised two solvents: (A) $0.1 \%(\mathrm{v} / \mathrm{v})$ formic acid in water and (B) $0.1 \%(\mathrm{v} / \mathrm{v})$ formic acid in acetonitrile/ water $(50: 50, v / v)$. A multistep gradient program was used at a flow rate of $0.40 \mathrm{~mL} / \mathrm{min}$, being the injection volume of $5 \mu \mathrm{L}$. Each chromatographic assay comprised a $10 \mathrm{~min}$ run.

MS detection was performed in positive mode by multiple reaction monitoring (MRM) with nitrogen served as the sheath gas (50 psi). The system was operated with a spray voltage of $5.5 \mathrm{kV}$, a source temperature of $400{ }^{\circ} \mathrm{C}$ and a capillary voltage of $18 \mathrm{~V}$. The tube lens offset was kept at a voltage of $25 \mathrm{~V}$. Mass spectra were acquired by full range acquisition covering $100-1500 \mathrm{~m} / \mathrm{z}$. The mass spectrometry parameters, confirmation and quantification mass transition $(\mathrm{m} / \mathrm{z})$, and their collision energies are shown in Table 1. Data acquisition was carried out with Xcalibur ${ }^{\circledast}$ data system (ThermoFinnigan, San Jose, CA, USA).

Peaks identification took into account the retention time ( $\mathrm{min}$ ), the quantification transition $(\mathrm{m} / \mathrm{z})$ and the confirmatory transition $(\mathrm{m} / \mathrm{z})$ data. It should be remarked that, since the amino acids detection/ quantification was based on mass detection, and two of the amino acids are isomers (leucine and isoleucine), their levels were quantified together as leucine-isoleucine. Stock standard solutions $(10 \mathrm{nmol} / \mu \mathrm{L})$ of each amino acid, were prepared using distilled water. Calibration curves were established for each of the 19 amino acids under analysis (8 essential, 11 non-essential amino acids) plus cystine for concentration dynamic ranges of $0-7 \mathrm{nmol} / \mu \mathrm{L}$. The internal standard (IS) method was used to calibrate the chromatographic system for the amino acids quantification, being the N-Acetyl-L-Tyrosine chosen as the IS since it was not detected in the protein fraction of the cheese samples analyzed. The calibration curves (Eq. (1)) were established by simple linear regression and their quality was assessed based on the linear regression coefficient of determination $\left(R^{2}\right)$, being calculated, for each amino acid the limits of detection and quantification (LOD and LOQ, respectively) using Eqs. (2) and (3) (Ermer \& Miller, 2005). 
Table 1

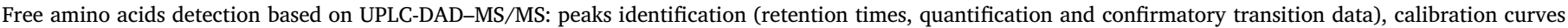
(slope, intercept and respective errors) and limits of detection (LOD, $\mu \mathrm{mol} / \mathrm{L})$ and quantification (LOQ, $\mu \mathrm{mol} / \mathrm{L})$.

\begin{tabular}{|c|c|c|c|c|c|c|c|c|}
\hline \multirow[t]{2}{*}{ Free amino acids } & \multirow{2}{*}{$\begin{array}{l}\text { Retention } \\
\text { time (min) }\end{array}$} & \multirow{2}{*}{$\begin{array}{l}\text { Quantification } \\
\text { transition }(m / z)\end{array}$} & \multirow{2}{*}{$\begin{array}{l}\text { Confirmatory } \\
\text { Transition }(m / z)\end{array}$} & \multirow{2}{*}{$\begin{array}{l}\text { Collision } \\
\text { energy (V) }\end{array}$} & Calibration curves* & & \multirow{2}{*}{$\begin{array}{l}\mathrm{LOD}^{\$} \\
-(\mu \mathrm{mol} / \mathrm{L})\end{array}$} & \multirow{2}{*}{$\begin{array}{l}\mathrm{LOQ}^{\#} \\
(\mu \mathrm{mol} / \mathrm{L})\end{array}$} \\
\hline & & & & & $\begin{array}{l}\text { Slope ( } \pm \text { error) }(\mu \mathrm{L} / \\
\text { nmol) }\end{array}$ & Intercept ( \pm error) & & \\
\hline
\end{tabular}

\begin{tabular}{|c|c|c|c|c|c|c|c|c|c|}
\hline \multicolumn{10}{|l|}{ Essential amino acids } \\
\hline Histidine (His) & 0.62 & 156 & 137, 111, 109, 94 & 25 & $6.2( \pm 0.2)$ & $-0.018( \pm 0.001)$ & 0.9987 & 0.42 & 1.28 \\
\hline $\begin{array}{l}\text { Leucine-Isoleucine } \\
\text { (Leu-Ile) }\end{array}$ & 0.82 & 132 & $\begin{array}{l}120,114,104,86 \\
85,71,68\end{array}$ & 25 & $23.5( \pm 0.2)$ & $-0.001( \pm 0.002)$ & 0.9996 & 0.37 & 1.13 \\
\hline Lysine (Lys) & 0.61 & 147 & $130,129,100$ & 25 & $12.8( \pm 0.1)$ & $-0.001( \pm 0.000)$ & 0.9996 & 0.21 & 0.62 \\
\hline Methionine (Met) & 0.76 & 150 & $132,103,101,55$ & 25 & $14.4( \pm 0.1)$ & $-0.000( \pm 0.000)$ & 0.9997 & 0.42 & 1.28 \\
\hline Phenylalanine (Phe) & 1.01 & 166 & $148,130,119$ & 25 & $17.6( \pm 0.1)$ & $-0.011( \pm 0.063)$ & 0.9992 & 41.5 & 126 \\
\hline Threonine (Thr) & 0.59 & 120 & $\begin{array}{l}101,99,83,73,71, \\
55\end{array}$ & 25 & $3.44( \pm 0.05)$ & $-0.000( \pm 0.000)$ & 0.9992 & 0.56 & 1.70 \\
\hline Tryptophan (Trp) & 1.46 & 205 & $187,159,132$ & 25 & $22.8( \pm 0.3)$ & $-0.002( \pm 0.001)$ & 0.9994 & 0.24 & 0.73 \\
\hline Valine (Val) & 0.67 & 117 & $100,90,71$ & 25 & $7.08( \pm 0.04)$ & $-0.000( \pm 0.000)$ & 0.9998 & 0.35 & 1.06 \\
\hline \multicolumn{10}{|c|}{ Non-essential amino acids } \\
\hline Alanine (Ala) & 0.65 & 90 & 68,61 & 18 & $0.009( \pm 0.000)$ & $0.000( \pm 0.000)$ & 0.9989 & 44.2 & 134 \\
\hline Arginine (Arg) & 0.62 & 175 & $\begin{array}{l}157,140,130,115 \\
111,97\end{array}$ & 30 & $13.0( \pm 0.2)$ & $-0.005( \pm 0.001)$ & 0.9994 & 0.29 & 0.88 \\
\hline Asparagine (Asn) & 0.82 & 133 & $\begin{array}{l}115,112,104,87 \\
89,85\end{array}$ & 25 & $4.74( \pm 0.05)$ & $-0.001( \pm 0.000)$ & 0.9995 & 0.44 & 1.35 \\
\hline Aspartic acid (Asp) & 0.60 & 134 & $115,87,86,73$ & 15 & $5.95( \pm 0.13)$ & $-0.000( \pm 0.000)$ & 0.9986 & 0.20 & 0.62 \\
\hline Cysteine (Cys) & 0.60 & 121 & $98,97,75$ & 25 & $0.169( \pm 0.005)$ & $-0.002( \pm 0.000)$ & 0.9981 & 1.20 & 3.62 \\
\hline Cystine (Cys-Cys) & 0.64 & 241 & $\begin{array}{l}224,14,177,168 \\
93,151\end{array}$ & 22 & $4.17( \pm 0.05)$ & $0.001( \pm 0.000)$ & 0.9995 & 0.49 & 1.49 \\
\hline Glutamic acid (Glu) & 0.61 & 148 & $130,129,101,83$ & 25 & $8.35( \pm 0.05)$ & $0.001( \pm 0.000)$ & 0.9998 & 0.40 & 1.22 \\
\hline Glutamine (Gln) & 0.61 & 147 & $129,100,83$ & 26 & $14.5( \pm 0.1)$ & $-0.003( \pm 0.002)$ & 0.9994 & 1.04 & 3.14 \\
\hline Glycine (Gly) & 0.65 & 76 & $75,47,29$ & 14 & $0.015( \pm 0.000)$ & $-0.000( \pm 0.000)$ & 0.9996 & 4.88 & 14.8 \\
\hline Proline (Pro) & 0.81 & 132 & 85 & 20 & $21.9( \pm 0.1)$ & $-0.009( \pm 0.003)$ & 0.9998 & 1.29 & 3.92 \\
\hline Tyrosine (Tyr) & 0.74 & 182 & 164,135 & 25 & $8.94( \pm 0.05)$ & $-0.001( \pm 0.001)$ & 0.9997 & 1.29 & 3.92 \\
\hline Serine (Ser) & 0.58 & 106 & $88,87,85,59$ & 25 & $1.07( \pm 0.02)$ & $0.000( \pm 0.000)$ & 0.9989 & 0.87 & 2.62 \\
\hline
\end{tabular}

* Calibration curves established by single linear regression according to Eq. (1).

$\$$ Limits of detection (LOD) calculated using Eq. (2).

\# Limits of quantification (LOQ) calculated using Eq. (3).

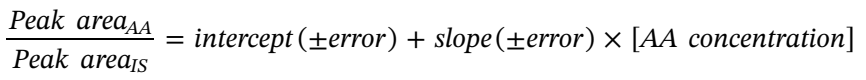

where, AA refers to each amino acid under analysis, IS refers to the AA used as internal standard, the peak areas are given in arbitrary units (a.u.) and the AA standard solution concentrations (in $\mathrm{nmol} / \mu \mathrm{L}$ ).

$L O D=3.3 \times \frac{S D_{\text {regression }}}{\text { slope }}$

$L O D=10 \times \frac{S D_{\text {regression }}}{\text { slope }}$

being $S D_{\text {regression }}$ the standard deviation (or error) of the regression.

\subsubsection{Cheese samples preparation}

From each cheese two independent samples of approximately $5.0 \mathrm{~g}$ were collected and inserted into flasks containing $10 \mathrm{~mL}$ of water:acetonitrile (50:50) (v/v) solution with $3.0 \mathrm{mM}$ of N-Acetyl-L-Tyrosine (used as the IS). The mixture was shaken using a vortex (LBX V05 series, LABBOX LABWARE S.L., Barcelona, Spain) at $500 \mathrm{rpm}$ for $5 \mathrm{~min}$ and then sonicated for $10 \mathrm{~min}$ at room temperature $\left(20^{\circ} \mathrm{C}\right)$. The samples were immediately centrifuged at $4^{\circ} \mathrm{C}$ and $10000 \mathrm{rpm}$ during $10 \mathrm{~min}$ (Heraeus Multifuge X1R, Thermo Fisher Scientific). The supernatant was filtered, under vacuum, through a $0.2 \mu \mathrm{m}$ Nylon membrane filter (Whatman PURADISC $25 \mathrm{NYL}$ ) and stored at $-4^{\circ} \mathrm{C}$ until analysis.

2.3. Contents of free amino acids, essential free amino acids, branched chain free amino acids and respective free amino acids ratios

The free amino acids contents determined by UPLC-DAD-MS/MS were used to calculate the sum of the free amino acids (FAA), essential free amino acids (EFAA) and branched chain free amino acids (BCFAA), for each cheese as follows:

$\sum F A A=\sum_{i=1}^{N_{F A A}}[F A A]_{i}$

where, $\sum F A A$ is the sum of the free amino acids levels quantified in the cheese sample (in $\mathrm{mg} / 100 \mathrm{~g}$ of cheese, wet matter), $[F A A]_{i}$ is the concentration of the free amino acid $i$ in the cheese sample (in $\mathrm{mg} / 100 \mathrm{~g}$ of cheese, wet matter), and $N_{\mathrm{AA}}$ is the number of free amino acids detected in each cheese sample,

$\sum E F A A=\sum_{j=1}^{N_{E F A A}}[E F A A]_{j}$

where, $\sum E F A A$ is the sum of essential free amino acids levels quantified in the cheese sample (in $\mathrm{mg} / 100 \mathrm{~g}$ of cheese, wet matter), $[E F A A]_{j}$ is the concentration of the essential free amino acid $j$ in the cheese sample (in $\mathrm{mg} / 100 \mathrm{~g}$ of cheese, wet matter), and $N_{E F A A}$ is the number of essential free amino acids detected in each cheese sample (i.e., histidine, leucine-isoleucine, lysine, methionine, phenylalanine, threonine, tryptophan and valine). EFAA are key parameters in food quality assessment (Almeida, Alvares, Costa, \& Conte-Junior, 2016; Tessari et al., 2016; Wilkinson et al., 2007).

$\sum B C F A A=\sum_{k=1}^{N_{B C F A A}}[B C F A A]_{k}$

where, $\triangle B C F A A$ is the sum of the branched chain free amino acids levels quantified in the cheese sample (in $\mathrm{mg} / 100 \mathrm{~g}$ of cheese, wet matter), $[B C F A A]_{k}$ is the concentration of the branched chain free amino acid $k$ in the cheese sample (in $\mathrm{mg} / 100 \mathrm{~g}$ of cheese, wet matter), and $N_{B C A A}$ is the number of branched chain free amino acids detected in 
Table 2

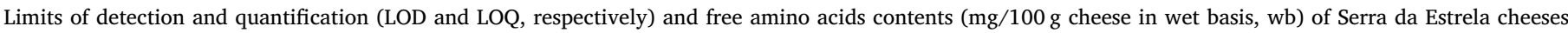

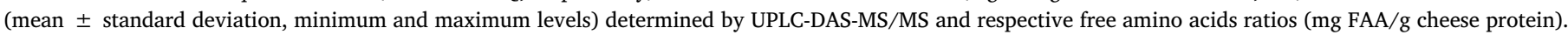

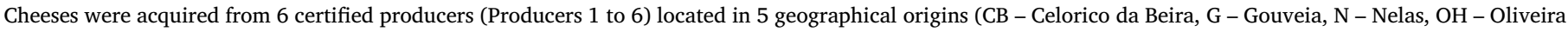
do Hospital and PC - Penalva do Castelo) and were produced during November 2017 to March 2018.

\begin{tabular}{|c|c|c|c|c|c|c|}
\hline \multirow[t]{2}{*}{ Free amino acids } & \multirow{2}{*}{$\begin{array}{l}\mathrm{LOD}^{\$}(\mathrm{mg} / 100 \mathrm{~g} \\
\text { cheese, wb) }\end{array}$} & \multirow{2}{*}{$\begin{array}{l}\mathrm{LOQ}^{\#}(\mathrm{mg} / 100 \mathrm{~g} \\
\text { cheese, wb) }\end{array}$} & \multicolumn{2}{|c|}{ Cheese contents* (mg/100 g cheese, wb) } & \multicolumn{2}{|c|}{ Free amino acids ratios ${ }^{\S}(\mathrm{mg} / \mathrm{g}$ cheese' crude protein) } \\
\hline & & & Mean \pm sd & Minimum-Maximum & Mean \pm sd & Minimum-Maximum \\
\hline \multicolumn{7}{|l|}{ Essential amino acids } \\
\hline Histidine (His) & 0.013 & 0.040 & $0.19 \pm 0.09$ & $0.07-0.47$ & $0.009 \pm 0.004$ & $0.003-0.018$ \\
\hline Leucine-Isoleucine (Leu-Ile) & 0.010 & 0.030 & $40 \pm 15$ & $12-74$ & $1.8 \pm 0.6$ & $0.6-3.1$ \\
\hline Lysine (Lys) & 0.006 & 0.018 & $0.34 \pm 0.30$ & $0.07-1.81$ & $0.015 \pm 0.011$ & $0.004-0.068$ \\
\hline Methionine (Met) & 0.012 & 0.038 & $1.1 \pm 0.8$ & $0.2-4.3$ & $0.05 \pm 0.04$ & $0.01-0.16$ \\
\hline Phenylalanine (Phe) & 1.372 & 4.158 & $23 \pm 10$ & $6-59$ & $1.0 \pm 0.4$ & $0.3-2.2$ \\
\hline Threonine (Thr) & 0.013 & 0.040 & $0.27 \pm 0.19$ & $0.09-1.1$ & $0.012 \pm 0.008$ & $0.004-0.042$ \\
\hline Tryptophan (Trp) & 0.010 & 0.030 & $2.2 \pm 1.7$ & $0.3-6.8$ & $0.10 \pm 0.08$ & $0.01-0.28$ \\
\hline Valine (Val) & 0.008 & 0.025 & $9.1 \pm 5.1$ & $0.05-21$ & $0.4 \pm 0.2$ & $0.002-0.865$ \\
\hline \multicolumn{7}{|l|}{ Non-essential amino acids } \\
\hline Alanine (Ala) & 0.787 & 2.385 & N.D. & - & - & - \\
\hline Arginine (Arg) & 0.010 & 0.030 & $0.11 \pm 0.07$ & $0.05-0.48$ & $0.005 \pm 0.003$ & $0.002-0.020$ \\
\hline Asparagine (Asn) & 0.012 & 0.036 & $24 \pm 14$ & $4-77$ & $1.1 \pm 0.5$ & $0.2-2.9$ \\
\hline Aspartic acid (Asp) & 0.005 & 0.016 & $0.79 \pm 0.57$ & $0.2-2.5$ & $0.04 \pm 0.02$ & $0.008-0.095$ \\
\hline Cysteine (Cys) & 0.029 & 0.088 & $75 \pm 27$ & $25-134$ & $3.4 \pm 1.4$ & $1.2-7.1$ \\
\hline Cystine (Cys-Cys) & 0.024 & 0.072 & N.D. & - & - & - \\
\hline Glutamic acid (Glu) & 0.012 & 0.036 & $2.0 \pm 2.7$ & $0.2-12$ & $0.09 \pm 0.12$ & $0.01-0.56$ \\
\hline Glutamine (Gln) & 0.030 & 0.092 & $0.35 \pm 0.41$ & $0.04-2.2$ & $0.02 \pm 0.02$ & $0.002-0.083$ \\
\hline Glycine (Gly) & 0.073 & 0.222 & N.D. & - & - & - \\
\hline Proline (Pro) & 0.030 & 0.090 & $33 \pm 12$ & $9-64$ & $1.5 \pm 0.5$ & $0.5-2.6$ \\
\hline Tyrosine (Tyr) & 0.047 & 0.142 & $1.0 \pm 1.4$ & $0.04-6.5$ & $0.04 \pm 0.06$ & $0.002-0.294$ \\
\hline Serine (Ser) & 0.018 & 0.055 & $0.52 \pm 0.28$ & $0.1-1.4$ & $0.03 \pm 0.01$ & $0.004-0.067$ \\
\hline
\end{tabular}

N.D.: not detected.

$\$$ Limits of detection (LOD), in $\mathrm{mg}$ of amino acid per $100 \mathrm{~g}$ of cheese, in wet basis (wb) calculated based on the values reported in Table 1

\# Limits of quantification (LOQ), in mg of FAA per $100 \mathrm{~g}$ of cheese, in wet basis (wb) calculated based on the values reported in Table 1.

* Free amino acids contents, in $\mathrm{mg}$ per $100 \mathrm{~g}$ of cheese (wet basis, wb): mean \pm standard deviation (sd), minimum and maximum levels found in the Serra da Estrela PDO cheeses (24 cheeses $\times 2$ independent samples $\times 3$ chromatographic runs).

$\S$ Free amino acids ratios, in $\mathrm{mg}$ of amino acid per $\mathrm{g}$ of cheese' crude protein, calculated using Eq. (7).

each cheese sample (i.e., leucine-isoleucine and valine).

The free amino acids ratios (FAAratio in $\mathrm{mg}$ FAA/g cheese protein) for each cheese sample were calculated (Brestenský et al., 2018; Nitrayová, Brestenský, \& Patráš, 2018; Tessari et al., 2016). In this work, the cheese protein data used (average level of $22 \pm 2 \%$, data not shown) were obtained by NIR spectrophotometry and previously reported by Reis Lima, Fontes, et al. (2019). In this work, these parameters correspond to the ratio of free amino acid content to the crude protein amount and may be used as a normalization technique, which minimizes the effect that the different cheeses' moisture levels may have in the final content of each free amino acid:

$F A A_{\text {ratio }}=\frac{\text { mass of } F A A(m g)}{\text { mass of crude protein }(g)}$

\subsection{Statistical analysis}

Simple linear regressions (LR) were used to establish the free amino acids chromatographic calibration curves, using the Data Analysis ToolPak of Microsoft Excel. The free amino acids data were subjected to one-way multivariate analysis of variance (one-way MANOVA) using general linear model (GLM) procedures being the cheese producer the fixed factor. For MANOVA analysis the Wilks' Lambda and Pillai Trace tests were used for inferring about the significance of the producer effect on the overall free amino acids profiles. Furthermore, one-way ANOVA was also applied for inferring about the possible effect of the cheese producer on the individual free amino acids contents. Linear discriminant analysis (LDA) was implemented coupled with the simulated annealing (SA) variable selection algorithm (Bertsimas \& Tsitsiklis, 1993; Cadima, Cerdeira, \& Minhoto, 2004; Kirkpatrick, Gelatt, \& Vecchi, 1983), which allows identifying the most discriminative variables that guaranteed obtaining the best predictive classification performance (i.e., the correct identification of Serra da Estrela cheese producer). The variables used included the sum of the free amino acids ( $\Sigma \mathrm{FAA}$ ), the sum of the essential free amino acids ( $\Sigma$ EFAA), the sum of the branched chain free amino acids ( $\Sigma \mathrm{BCFAA}$ ) and the 16 related free amino acids ratios $\left(\mathrm{FAA}_{\text {ratio; }}\right.$ mg FAA/g crude protein). The LDA-SA performance was assessed using the leave-one-out cross-validation (LOO-CV) procedure, which although being an overoptimistic internal validation technique has been widely used when the number of samples is limited. To further normalize the weight of each variable in the final linear classification model, variable scaling and centering procedures were evaluated. The LDA-SA classification potential was further checked using the repeated K-fold internal crossvalidation procedure (repeated K-fold-CV). In this work the number of $\mathrm{K}$-folds was set equal to 4 , enabling the random formation of internal validation subsets (for each producer) with $25 \%$ of initial data allowing bias reduction, being the split procedure repeated 10 times. The repeated K-fold-CV allowed evaluating the predictive performance of the LDA-SA models established using $4 \times 10$ random sub-sets for internal validation (i.e., 40 total resamples), being in each run $25 \%$ of the initial database set apart for validation purposes and the other $75 \%$ of the data used to establish the best discriminant model. The LDA-SA analysis was performed using the Subselect (Cadima et al., 2004, 2012) and MASS (Venables \& Ripley, 2002) packages of the open source statistical program R (version 2.15.1), at a 5\% significance level. 


\section{Results and discussion}

\subsection{Amino acids chromatographic analysis: Peaks identification, calibration curves, detection and quantification limits}

In this study, an UPLC-DAD-MS/MS chromatographic method was applied to detect and quantify amino acids contents in Serra da Estrela cheeses. The UPLC-DAD-MS/MS allowed to establish calibration curves $\left(0.9981 \leq R^{2} \leq 0.9998\right.$; Eq. (1)) for 19 amino acids plus cystine, being the isomers leucine and isoleucine assessed simultaneously since they have the same molecular weight, and their chromatographic separation was not possible with the used method. In general low limits of detection and quantification (LOD and LOQ, calculated using Eqs. (2) and (3), respectively), were obtained (Table 1), with the exception of phenylalanine, alanine and glycine. In total 19 amino acids, including both essential (histidine, leucine-isoleucine, lysine, methionine, phenylalanine, threonine, tryptophan and valine) and non-essential amino acids (alanine, arginine, asparagine, aspartic acid, cysteine, cystine, glutamine, glutamic acid, glycine, proline, tyrosine and serine) plus cystine, the oxidized dimer form of the amino acid cysteine, could be chromatographically detected, being the respective peaks identified using the retention times, quantification transition and confirmatory transition data (Table 1).

\subsection{Free amino acids chromatographic analysis in cheese samples}

The UPLC-DAD-MS/MS technique was used to detect and quantify the free amino acids levels presented in the Serra da Estrela cheeses, collected after 45 days of maturation (Table 2). From the 19 free amino acids that the chromatographic method was capable to detect, 2 nonessential free amino acids (alanine and glycine) were not detected in any of the cheeses, being cystine, the oxidized dimer form of cysteine, also not detected. So, only 17 free amino acids could be detected in the cheese samples. Thus, it could be concluded that, the evaluated cheeses, with 45 days of maturation, did not contain alanine or glycine, neither cystine or that their concentrations in the cheeses were lower than $0.787,0.073$ and $0.024 \mathrm{mg} / 100 \mathrm{~g}$ cheese (wb) (i.e., limits of detection of the abovementioned compounds), respectively and so, could not be detected with the detector/chromatographic method used in this work (Table 2). The other essential and non-essential free amino acids were detected and quantified in all cheese samples with mean values ( \pm standard deviations) ranging from $0.11 \pm 0.07$ to $75 \pm 27 \mathrm{mg}$ / $100 \mathrm{~g}$ cheese $(\mathrm{wb})$ for arginine and cysteine, respectively. Moreover, it was found that the evaluated Serra da Estrela cheeses had mean global contents ( \pm standard deviations) of free amino acids ( $\mathrm{FFA}$ ) of $212 \pm 75 \mathrm{mg} / 100 \mathrm{~g}$ cheese (wb) (ranging from 63 to $429 \mathrm{mg} / 100 \mathrm{~g}$ cheese, wb), of essential free amino acids ( $\Sigma \mathrm{EFAA}$ ) of $75 \pm 30 \mathrm{mg}$ / $100 \mathrm{~g}$ cheese (wb) (ranging from 19 to $167 \mathrm{mg} / 100 \mathrm{~g}$ cheese, wb), of non-essential free amino acids (INEFAA) of $136 \pm 46 \mathrm{mg} / 100 \mathrm{~g}$ cheese (wb) (ranging from 44 to $262 \mathrm{mg} / 100 \mathrm{~g}$ cheese, wb) and of branched chain free amino acids ( $\mathrm{BCFAA}$ ) of $49 \pm 19 \mathrm{mg} / 100 \mathrm{~g}$ cheese (wb) (ranging from 12 to $95 \mathrm{mg} / 100 \mathrm{~g}$ cheese, wb). The presence of these free amino acids, which is related to proteolysis, may foresee that the total levels of amino acids in Serra da Estrela cheeses would be higher since most of the cheeses' amino acids are within the protein and polypeptides chains, being only available after hydrolysis. It should be remarked that the free amino acids contents of the studied cheeses showed quite high standard deviations as well as broad minimum-maximum ranges (Table 2). This variability could be tentatively attributed to the intrinsic composition variability of the cheeses that were acquired from 6 different certified producers located at 5 different municipalities within the PDO region and produced during 5 months (from November 2017 until March 2018). Indeed, the oneway MANOVA's results showed that cheese producer had a significant statistical effect on the overall free amino acids profile ( $P$-value $<$ 0.001 , obtained by the Wilks' Lambda and Pillai Trace tests). Also, the contents of each of the 17 free amino acids detected in the cheese samples significantly varied with the cheese producer $(P$-value $<0.05$ for the one-way ANOVA), although without any evident trend, being not possible to conclude that all cheeses from a specific producer were richer in a group of amino acids (e.g., essential versus non-essential free amino acids). On the other hand, it could be observed that the cheeses acquired from Producers 1 and 4 had statistical significant lower total global levels ( $P$-value $<0.001$ for one-way ANOVA) of free amino acids ( $\Sigma F A A)$, essential free amino acids ( $\Sigma E A A)$ and branched chain free amino acids ( $\Sigma$ BCFAA) than the cheeses obtained from the other 3 cheese producers. However, the producer significant statistical influence observed on the cheeses' free amino acids contents, which could foresee the use of the latter as potential discriminant variables, should be regarded with caution since the majority of the amino acids are comprised on the protein chains and this evaluation was not performed as it was not the focus of the present work. In addition, cheese production comprises several technological and biochemical processes that occur from raw milk till the end of the maturation period, which differences among producers were not possible to fully considered in this study.

Still, the free amino acids contents found in this work were similar to those reported by Tavaria Franco Carballo \& Malcata (2003) for Serra da Estrela cheeses (20 cheeses), produced on the same day in four dairy factories located in the official demarcated region. It should be remarked that, the overall free amino acids levels found in the present study $(\Sigma F A A=416 \pm 152 \mathrm{mg} / \mathrm{g} \mathrm{DM}$, considering the mean cheeses' moisture levels of $49 \pm 3 \%$ ) were of the same order of magnitude but slightly lower than those reported by Tavaria et al. (2003), for cheeses with similar ripening times and produced from non-refrigerated ewe milks $(88 \pm 173$ or $720 \pm 160 \mathrm{mg} / \mathrm{g} \mathrm{DM}$, for 35 and 60 days of ripening, respectively) or produced with refrigerated ewe milk (1416 $\pm 13 \mathrm{mg} / \mathrm{g} \mathrm{DM}$, for 60 days of ripening). On the other hand, the global amino acids levels of the cheeses evaluated are slightly greater than those reported for Krk cheese (Radeljević et al., 2013), a Croatian cheese also produced with ewe's milk (148 \pm 50 or $234 \pm 60 \mathrm{mg} / \mathrm{g}$ $\mathrm{DM}$, for 30 or 60 days of ripening, respectively). Contrary to the findings of Tavaria et al. (2003) and as already mentioned, in the present work, alanine, cystine and glycine were not detected in the cheese samples studied. However, it should be noticed that cheese is a complex and heterogeneous food product, which composition is highly variable. In fact, for example, the amino acids profiles and contents (individual and total) are highly dependent on the ripening time (being expected an increase of the amino acids levels with the ripening time), type of milk (cow, ewe, goat or mixtures), refrigeration conditions of milk (non-refrigerated versus refrigerated), the use or not of lactic acid bacteria strains co-cultures as well as the technological procedures used on cheese production (Balabanova et al., 2017; Ceruti, Zorrilla, \& Sihufe, 2012; De Pasquale, Di Cagno, Buchin, De Angelis, \& Gobbetti, 2019; del Olmo, López-Pérez, Picon, Gaya, \& Nuñez, 2019; Eren-Vapur \& Ozcan, 2012; Parlak \& Guzeler, 2016; Renes, Ladero, Tornadijo, \& Fresno, 2019; Tavaria et al., 2003; Tekin \& Güler, 2019; Zheng et al., 2018).

Furthermore, as can be inferred form the data of Table 2 (standard deviation values) the free amino acids ratios (mg/g crude protein) showed a lower variability compared to the individual free amino acids levels, pointing out that the former parameters could be a better way of representing the true amino acids levels in the evaluated cheeses. The individual calculated free amino acid ratios $\left(\mathrm{FAA}_{\text {ratio }}\right)$, for the essential amino acids ranged from 0.003 to $3.1 \mathrm{mg} / \mathrm{g}$ protein with an average overall value of $3.5 \pm 1.3 \mathrm{mg} / \mathrm{g}$ protein (ranging from 1.0 to $6.4 \mathrm{mg} / \mathrm{g}$ protein). Thus, although cheese would be a minor source of essential free amino acids taking into account the daily intake of amino acid in adults recommended by the Food and Agriculture Organization (FAO) of the United Nations (ranging from 140 to $300 \mathrm{mg} / \mathrm{g}$ ) (Brestenský et al., 2018), the consumption of Serra da Estrela cheeses may contribute to fulfill this requirement, mainly since it is known that the total contents of amino acids are significantly greater than the total contents 
of free amino acids, as most of the amino acids are not derived from proteolysis but are comprised within the protein and polypeptides chains, which were not evaluated in the present study.

The observed variability of the free amino acids contents and, in a less extent of the related ratios, (Table 2), which could be partially explained by the different producers and production time-periods, pointed out the possibility of using this information or the related free amino acids ratios as possible cheese origin biomarkers, even if the free amino acids could only be quantified in low levels in the studied cheeses, being minor cheese constituents. Indeed, amino acids profiles, together with other compounds showed to be chemical fingerprints allowing discriminating PDO and non-PDO Grana Padano cheeses (Rocchetti et al., 2018). On the other hand, the fatty acids profiles of Serra da Estrela cheeses showed to be powerful chemical fingerprints enabling the successful discrimination of cheeses according to the producer, geographical origin and production time-period (Reis Lima, Bahri, et al., 2019).

3.3. Potential use of data on free amino acids, essential free amino acids, branched-chain free amino acids and free amino acids ratios for cheese producers' discrimination

Taking into account the economic and social impacts of the commercialization of Serra da Estrela cheese (roughly 20 million of euros per year and around 3000 direct depending families spread throughout the PDO geographical territory), the capability of identifying the cheese producer/brand (i.e., dairy industries) is of utmost economic importance, guaranteeing the cheese manufacturing authenticity and enhancing the consumers' confidence when purchasing and consuming this high-value food product. Recently, Serra da Estrela cheeses' fatty acids were successfully used to discriminate (LDA-SA model) cheese producers $(92 \%$ and $81 \%$ of correct classifications for the original grouped data and LOO-CV procedure), geographical origin (96\% and $88 \%$ of correct classifications for the original grouped data and LOO-CV procedure) and production time-periods (98\% and $71 \%$ of correct classifications for the original grouped data and $\mathrm{LOO}-\mathrm{CV}$ procedure) (Reis Lima, Bahri, et al., 2019). Although contrary to the fatty acids, the free amino acids were detected in low amounts, the possibility of using them as origin discriminating variables is also interesting, although their contents are highly dependent on maturation time, milk type, and technological production procedures. In this context, global levels of free amino acids, essential free amino acids, branched chain free amino acids and the related free amino acids quality ratios ( $\Sigma F A A, \Sigma E F A A$, $\Sigma$ BCFAA and FAA $_{\text {ratios }}$ ) were used to establish LDA-SA classification predictive models for identifying the Serra da Estrela cheese producer (among 6 possible certified producers located at 5 municipalities within the PDO territorial region and produced during 5 consecutive months). A LDA-SA (linear discriminant analysis-simulated annealing) model, with 5 significant discriminant functions (explaining the first 3 functions more than $92 \%$ of the total variance) was established based on the contents of $\Sigma F A A, \Sigma E F A A, \Sigma B C F A A$ (in mg/100 g cheese, wb) and 9 FAA $_{\text {ratios }}\left(\mathrm{FAA}_{\text {ratio-Cys }}, \mathrm{FAA}_{\text {ratio-Asn }}, \mathrm{FAA}_{\text {ratio-Gln }}, \mathrm{FAA}_{\text {ratio-Ser }}, \mathrm{FAA}_{\text {ratio-Thr }}\right.$, $\mathrm{FAA}_{\text {ratio-Met }}, \mathrm{FAA}_{\text {ratio-Pro, }} \mathrm{FAA}_{\text {ratio-Phe }}$ and $\mathrm{FAA}_{\text {ratio-Trp}}$, in $\mathrm{mg} / \mathrm{g}$ crude protein), which were selected by the SA algorithm, from the 19 initial variables dataset. It should be remarked that the variables selected were those with the most discrimination potential although the values reported in the present study, were determined considering only the free amino acids contents, not taking into account the amino acids within the protein chains of the cheeses, and so, must be regarded as default levels. The classification multivariate linear model correctly classified $98 \%$ of the original grouped data (Fig. 1) and $96 \%$ of the cheese samples using the LOO-CV procedure. For the latter internal-validation technique the individual selectivity (true positive percentage or probability of detection) varied from 80 to $100 \%$ and the individual specificity (true negative percentage) ranged from 89 to $100 \%$. The overall satisfactory predictive performance was further evaluated using the repeated K-fold-CV procedure (with 10 repetitions), a more realistic and robust $\mathrm{CV}$ variant. In this study, $\mathrm{K}$ was set equal to 4 , guaranteeing that at each run, $25 \%$ of the cheese samples (i.e., 12 samples, being 2 per producer) were kept at a time for validation purposes and the other $75 \%$ of the samples were used for training purposes. In which concerns the prediction of the cheese producer (dairy industry) the best classification results were found for the LDA model comprising the same 12 parameters previously listed, allowing an average predictive correct classification of $90 \pm 8 \%$ (sensitivities ranging from $77 \%$ to $100 \%$ for the 40 evaluations performed during the repeated K-fold-CV procedure).

Although the predictive classification performance regarding the cheese producer identification, achieved using the free amino acids data were better compared with that previously reported by Reis Lima, Bahri, et al. (2019) using the cheeses' fatty acids profiles, the former was slightly less well succeeded when trying to predict the production date (sensitivity of $67 \%$ for LOO-CV procedure, data not shown), showing that the free amino acids contents were more influenced by the dairy industry specifications (composition of the raw milk used and the specific and different technological singularities used by each producer) than the production date. On the other hand, if the individual free amino acids contents were used instead of the related protein ratios, the LDA-SA models established possessed a lower predictive discrimination capability, leading to only $92 \%$ of correct cheese classification by producer (LOO-CV, data not shown). This finding may indicate that the use of the protein ratios, an indirect normalization procedure of the free amino acids levels (taking into account the total protein content of each cheese), could enhance their discrimination power. Nevertheless, the results obtained in the present work clearly demonstrate that the free amino acids (namely the global free levels) and their related protein ratios could be used as preliminary potential discriminative variables for assessing Serra da Estrela cheese producer and so guaranteeing the cheeses origin. Still, cheese is a high complex food matrix, consequently, the establishment of a cheese traceability system would require inclusion of other cheese metabolites in a global composition data fusion chemometric strategy.

\section{Conclusions}

Serra da Estrela cheeses after 45 day of ripening contained both essential and non-essential free amino acids although in low contents (ranging from $0.19 \pm 0.09$ to $75 \pm 27 \mathrm{mg} / 100 \mathrm{~g}$ cheese in wet basis), even if the average relative protein abundance was quite important $(22 \pm 2 \%)$, which could be attributed to the fact that only the amino acids generated by the proteolysis were evaluated, being not quantified those comprised within the protein chains. The amounts of essential and branched chain free amino acids $(75 \pm 30$ and $49 \pm 19 \mathrm{mg} / 100 \mathrm{~g}$ cheese $\mathrm{wb}$, respectively), show that the consumption of this cheese may contribute to fulfill the recommended daily intake of amino acid in adults. Interesting, though it was not the main objective, this study showed that the cheeses' contents of the free amino acids significantly varied, being mainly influenced by the cheese producer than by the production time-period. This variability allowed verifying that the cheese free amino acids profiles and their related protein ratios (mass of free amino acid per mass of cheese protein) could be used to identify the cheese producer, with a satisfactory overall sensitivity and specificity, which were slightly greater than those obtained when fatty acids were used as discrimination biomarkers. This capability is of utmost relevance from a consumer and producer point of views since it enhances the confidence on the commercialization of this high price and appreciated cheese. These findings clearly pointed out that the amino acids per se or merged with other physicochemical data may be used, in the future, as a practical and accurate origin authentication tool for Serra da Estrela cheeses, or even for other maturation-type natural cheeses, once their profiles are established. 


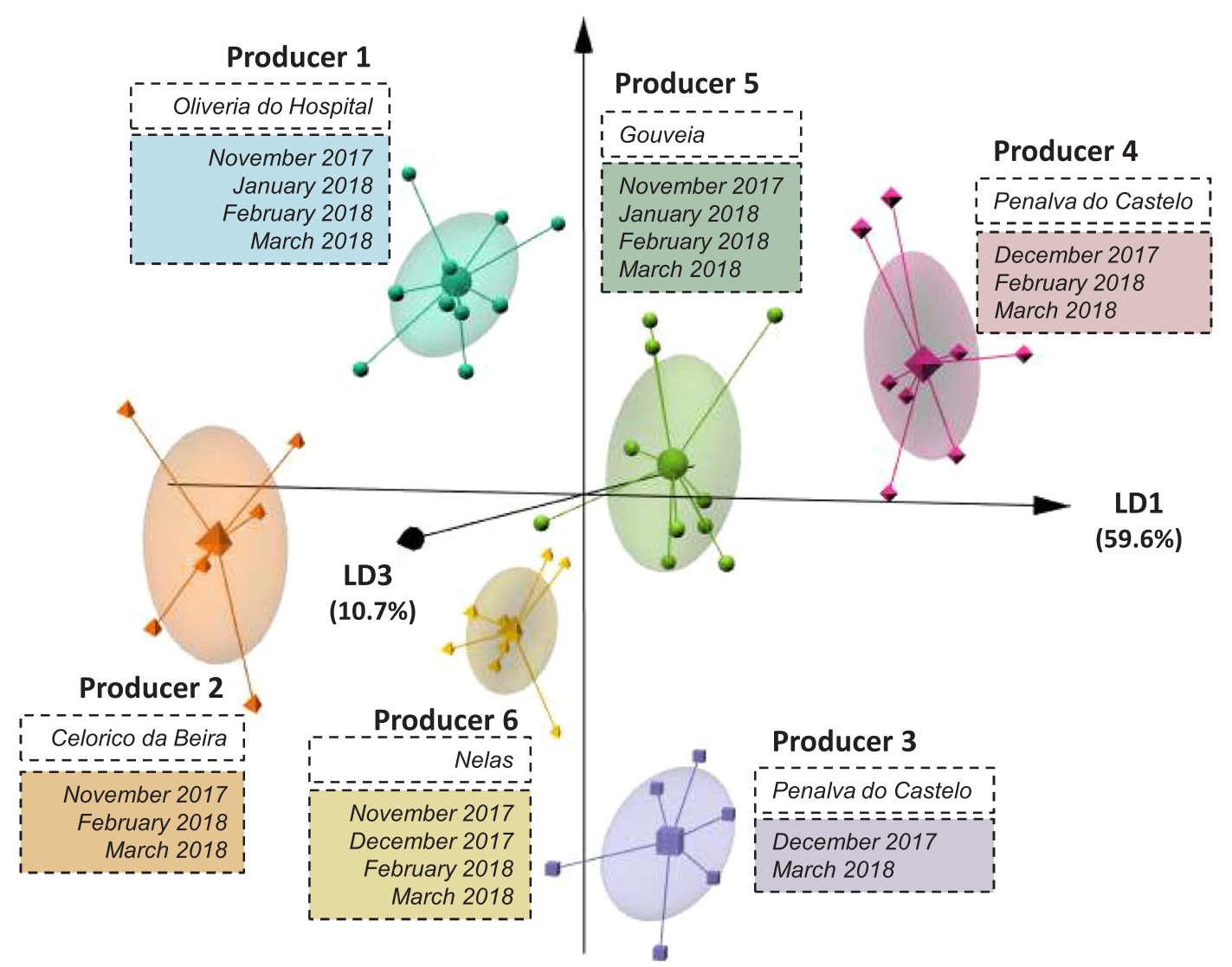

Fig. 1. LDA-SA classification model of Serra da Estrela PDO cheeses (24 cheeses $\times 2$ independent samples) according to the cheese producer (Producer 1 to 6), regardless the geographical origin (5 municipalities within the delimited PDO region) or the production date (5 months, ranging from November 2017 to March 2018): 3D plots of the first 3 most significant discriminant functions based on the contents of free amino acids ( $\Sigma \mathrm{AA}$, in $\mathrm{mg} / 100 \mathrm{~g}$ wet basis), essential free amino acids ( $\Sigma \mathrm{EAA}$, in $\mathrm{mg} / 100 \mathrm{~g}$ wet basis), branched chain free amino acids ( $\Sigma \mathrm{BCAA}$, in $\mathrm{mg} / 100 \mathrm{~g}$ wet basis) and the free amino acids ratios (FAA $\mathrm{ratios}$, in $\mathrm{mg} / \mathrm{g}$ cheese pcrude rotein) for cysteine, asparagine, glutamine, serine, threonine, methionine, proline, phenylalanine and tryptophan.

\section{Compliance with ethics requirements}

Conflict of Interest: The authors declare no conflict of interest. Ethical approval: This article does not contain any studies with human participants or animals performed by any of the authors. Informed Consent: Not applicable.

\section{Acknowledgments}

This work was financially supported by Associate Laboratory LSRELCM - UID/EQU/50020/2019, strategic funding UID/BIO/04469/ 2019-CEB and BioTecNorte operation (NORTE-01-0145-FEDER000004), and strategic project PEst-OE/AGR/UI0690/2014-CIMO funded by - funded by national funds through FCT/MCTES (PIDDAC). The authors would also like to acknowledge the funding provided by the approved Project, with reference 02/SAICT/ 2016/23290, entitled Characterization and Valorization of QSE PDO and its ability for health promotion (QCLASSE), financed by FCT. S. I. Falcão thanks National funding by FCT- Foundation for Science and Technology, P.I., through the institutional scientific employment program-contract.

\section{References}

Almeida, C. C., Alvares, T. S., Costa, M. P., \& Conte-Junior, C. A. (2016). Protein and amino acid profiles of different whey protein supplements. Journal of Dietary Supplements, 13(3), 313-323. https://doi.org/10.3109/19390211.2015.1036187. Balabanova, T., Ivanova, M., \& Vlaseva, R. (2017). Effect of rennet type and ripening period on chemical properties of Bulgarian white brined cheese. International Food Research Journal, 24(6), 2414-2418.

Bertsimas, D., \& Tsitsiklis, J. (1993). Simulated annealing. Statistical Science, 8, 10-15. https://doi.org/10.1214/ss/1177011077.

Brestenský, M., Nitrayová, S., Patráš, P., \& Nitray, J. (2018). Dietary requirements for proteins and amino acids in human nutrition. Current Nutrition \& Food Science, 14, 1-8. https://doi.org/10.2174/1573401314666180507123506.

Cadima, J., Cerdeira, J. O., \& Minhoto, M. (2004). Computational aspects of algorithms for variable selection in the context of principal components. Computational Statistics \& Data Analysis, 47, 225-236. https://doi.org/10.1016/j.csda.2003.11.001.519.

Cadima, J., Cerdeira, J. O., Silva, P. D., \& Minhoto M., 2012. The subselect R package. http://cran.rproject.org/web/packages/subselect/vignettes/subselect.pdf/ (accessed date: 12 December 2018)

Ceruti, R. J., Zorrilla, S. E., \& Sihufe, G. A. (2012). The influence of elevated initial ripening temperature on the proteolysis in Reggianito cheese. Food Research International, 48, 34-40. https://doi.org/10.1016/j.foodres.2012.02.011.

De Pasquale, I., Di Cagno, R., Buchin, S., De Angelis, M., \& Gobbetti, M. (2019). Use of autochthonous mesophilic lactic acid bacteria as starter cultures for making Pecorino Crotonese cheese: Effect on compositional, microbiological and biochemical attributes. Food Research International, 116, 1344-1356. https://doi.org/10.1016/j. foodres.2018.10.024.

del Olmo, A., López-Pérez, O., Picon, A., Gaya, P., \& Nuñez, M. (2019). Cheese supplementation with five species of edible seaweeds: Effect on proteolysis, lipolysis and volatile compounds. International Dairy Journal, 90, 104-113. https://doi.org/10. 1016/j.idairyj.2018.11.012.

Eren-Vapur, U., \& Ozcan, T. (2012). Determination of free amino acids in whole-fat Turkish White Brined Cheese produced by animal and microbial milk-clotting enzymes with and without the addition of starter culture. Mljekarstvo, 62, 241-250.

Ermer, J., \& Miller, J. (2005). Method Validation in Pharmaceutical Analysis: A Guide to Best Practice. Wiley: New York: Wiley-VCH GmbH and Co. KGaA. Weinheim ISBN: 3-52731255-2.

Guiné, R. P. F., Tenreiro, M. I. C., Correia, A. C., Correia, P. M. R., \& Barracosa, P. (2016). Analysis of factors influencing the physical, chemical and sensorial properties of Serra da Estrela cheeses. Journal of Food Measurement and Characterization, 10, 643-657. https://doi.org/10.1007/s11694-016-9348-6. 
Kirkpatrick, S., Gelatt, C. D., \& Vecchi, M. P. (1983). Optimization by simulated annealing. Science, 220, 671-680.

Nitrayová, S., Brestenský, M., \& Patráš, P. (2018). Comparison of two methods of protein quality evaluation in rice, rye and barley as food protein sources in human nutrition. Potravinarstvo Slovak Journal of Food Sciences, 12, 762-766. https://doi.org/10.5219/ 991.

Ochi, H., Sakai, Y., Koishihara, H., Abe, F., Bamba, T., \& Fukusaki, E. (2013). Monitoring the ripening process of Cheddar cheese based on hydrophilic component profiling using gas chromatography-mass spectrometry. Journal of Dairy Science, 96, 7427-7441. https://doi.org/10.3168/jds.2013-6897.

Parlak, Y., \& Guzeler, N. (2016). Nuclear magnetic resonance spectroscopy applications in foods. Current Research in Nutrition and Food Science, 4, 161-168.

Radeljević, B., Mikulec, N., Antunac, N., Prpić, Z., Maletić, M., \& Havranek, J. (2013). Influence of starter culture on total free aminoacids concentration during ripening of Krk cheese. Mljekarstvo, 63, 15-21.

Reis Lima, M. J., Bahri, H., Sá Morais, J., Veloso, A. C. A., Fontes, L., Lemos, E. T., \& Peres, A. M. (2019). Assessing Serra da Estrela PDO cheeses' origin-production date using fatty acids profiles. Journal of Food Measurement and Characterization. https://doi. org/10.1007/s11694-019-00219-z.

Reis Lima, M. J., Fontes, L., Bahri, H., Veloso, A. C. A., Lemos, E. T., \& Peres, A. M. (2019). Fatty acids profile of Serra da Estrela PDO cheeses and respective atherogenic and thrombogenic indices. Nutrition and Food Science. https://doi.org/10.1108/NFS-062019-0178.

Renes, E., Ladero, V., Tornadijo, M. E., \& Fresno, J. M. (2019). Production of sheep milk cheese with high $\gamma$-aminobutyric acid and ornithine concentration and with reduced biogenic amines level using autochthonous lactic acid bacteria strains. Food Microbiology, 78, 1-10. https://doi.org/10.1016/j.fm.2018.09.003.

Rocchetti, G., Lucini, L., Gallo, A., Masoero, F., Trevisan, M., \& Giuberti, G. (2018). Untargeted metabolomics reveals differences in chemical fingerprints between PDO and non-PDO Grana Padano cheeses. Food Research International, 113, 407-413. https://doi.org/10.1016/j.foodres.2018.07.029

Subramanian, A., Harper, W. J., \& Rodriguez-Saona, L. E. (2009). Cheddar cheese classification based on flavor quality using a novel extraction method and Fourier transform infrared spectroscopy. Journal of Dairy Science, 92, 87-94. https://doi.org/ 10.3168/jds.2008-1449.

Succi, M., Aponte, M., Tremonte, P., Niro, S., Sorrentino, E., Iorizzo, M., ... Coppola, R. (2016). Variability in chemical and microbiological profiles of long-ripened Caciocavallo cheeses. Journal of Dairy Science, 99, 9521-9533. https://doi.org/10. 3168/jds.2016-11585.

Tavaria, F. K., Franco, I., Carballo, F. J., \& Malcata, F. X. (2003). Amino acid and soluble nitrogen evolution throughout ripening of Serra da Estrela cheese. International Dairy Journal, 13, 537-545. https://doi.org/10.1016/S0958-6946(03)00060-8.

Tekin, A., \& Güler, Z. (2019). Glycolysis, lipolysis and proteolysis in raw sheep milk Tulum cheese during production and ripening: Effect of ripening materials. Food Chemistry, 286, 160-169. https://doi.org/10.1016/j.foodchem.2019.01.190.

Tessari, P., Lante, A., \& Mosca, G. (2016). Essential amino acids: Master regulators of nutrition and environmental footprint? Scientific Reports, 6. https://doi.org/10.1038/ srep 26074 .

Venables, W. N., \& Ripley, B. D. (2002). Modern applied statistics with S (statistics and computing) (4th ed.). New York: Springer.

Wilkinson, S. B., Tarnopolsky, M. A., MacDonald, M. J., MacDonald, J. R., Armstrong, D., \& Phillips, S. M. (2007). Consumption of fluid skim milk promotes greater muscle protein accretion after resistance exercise than does consumption of an isonitrogenous and isoenergetic soy-protein beverage. American Journal of Clinical Nutrition, 85, 1031-1040.

Zheng, X., Liu, F., Shi, X., Wang, B., Li, K., Li, B., \& Zhuge, B. (2018). Dynamic correlations between microbiota succession and flavor development involved in the ripening of Kazak artisanal cheese. Food Research International, 105, 733-742. https://doi.org/ 10.1016/j.foodres.2017.12.007. 